\title{
ANALYSIS OF THE RESULTS OF AN EXPERIMENTAL STUDY OF THE PROCESS OF VAPOR CONDENSATION FROM VAPOR-GAS MIXTURE ON THE SURFACE OF THE CYLINDRICAL FREE-DRAINING LIQUID JET (PART 1)
}

\author{
V. Bondar, K. Solodka, S. Vasilenko \\ National University of Food Technologies
}

\begin{tabular}{l}
$\quad$ Key words: \\
Condensation \\
Heat transfer \\
Heat and mass transfer \\
apparatus \\
Mathematical Model \\
Hydrodynamic \\
characteristics \\
\hline
\end{tabular}

Article history:

Received 09.01.2018

Received in revised form

29.01.2018

Accepted 05.02.2018

Corresponding author:

V. Bondar

E-mail:

npnuht@ukr.net

\begin{abstract}
As a result of the analysis of existing outcomes of vapor condensation on the free-draining liquid jet, a conclusion can be made about the existence of a significant number of models that describe these processes of heat transfer. But the vast majority of these correlations are based on the experimental approach, and only for those ranges of data for which the study was conducted.

Accordingly, an experimental study of the heat transfer process during steam condensation on the surface of cylindrical jets of a not bearable liquid of various geometric parameters at different flow characteristics of the steam flow must be conducted according to the operating conditions of heat-massexchange machines of food production as well as a theoretical study of the process of heat transfer during condensation of vapors on the surface of cylindrical jets of a not bearable liquid.

For studying the heat transfer processes in the range of consumables and operating parameters changing of the flow of liquid and vapor, that are mostly close to the modes of heat transfer equipment of the food industry, a test facility, for studying the processes of heat exchange during vapor condensation on a cylindrical free-draining liquid jet, was designed and manufactured.
\end{abstract}

A preliminary analysis of experimental data of the heat exchange process was made and it was determined that it is impossible to use the existing mathematical models that can reliably accurate describe the heat transfer processes while vapor condensation on a cylindrical free-draining liquid jet for those modes of vapor and water motions in the range of which an experiment was conducted.

It is determined that the usage of existing models for generalization of experimental data of the conducted experiment is impossible. That is, nowadays there is no model that can reliably accurate describe the heat transfer processes while vapor condensation on a cylindrical free-draining liquid jet for those modes of vapor and water motions in the range of which an experiment was conducted.

DOI: $10.24263 / 2225-2924-2018-24-1-22$ 


\title{
АНАЛІЗ РЕЗУЛЬТАТІВ ЕКСПЕРИМЕНТАЛЬНОГО ДОСЛІДЖЕННЯ ПРОЦЕСУ КОНДЕНСАЦІЇ ПАРИ 3 ПАРОГАЗОВОЇ СУМІШІ НА ПОВЕРХНІ ЦИЛІНДРИЧНОГО ВІЛЬНОСТІКАЮЧОГО СТРУМЕНЯ РІДИНИ (ЧАСТИНА 1)
}

\author{
В.I. Бондар, К.М. Солодка, С.М. Василенко \\ Національний університет харчових технологій
}

У результаті аналізу існуючих результатів процесу конденсації пари на вільному струмені рідини можна зробити висновок про існування значної кількості моделей, які описують изі процеси теплопередачі. Але переважна більшість ичих корелячуій базується на експериментальному підході $і$ тільки для тих діапазонів даних, для яких було проведено дослідження.

3 огляду на иее необхідно провести експериментальне дослідження прочесу теплообміну під час конденсації пари на поверхні изиліндричних струменів нестисливої рідини різних геометричних параметрів при різних витратних характеристиках пароструминних потоків відповідно до умов роботи тепломасообмінних апаратів харчових виробництв, а також теоретичне дослідження процесу теплообміну під час конденсації пари на поверхні циліндричних струменів нестисливої рідини.

Розроблено та виготовлено дослідну установку для дослідження прочесів теплообміну під час конденсачії водяної пари на цчиліндричному вільностікаючому струмені рідини.

Проведено попередній аналіз дослідних даних процесу теплообміну та доведено неможливість використання існуючих математичних моделей, які б з достовірною точністю описували процеси теплообміну під час конденсації пари на циліндричному вільностікаючому струмені рідини для тих режимів руху водяної пари та води, в межах яких було проведено експеримент.

Встановлено щуо використання існуючих моделей для узагальнення дослідних даних проведеного експерименту неможливе. Тобто на сьогодні не існує моделі, яка б з достовірною точністю описувала процеси теплообміну під час конденсації пари на циліндричному вільностікаючому струмені рідини для тих режимів руху водяної пари та води, в межах яких було проведено експеримент.

Ключові слова: конденсація, теплообмін, тепломасообмінні апарати, математична модель, гідродинамічні характеристики.

Постановка проблеми. На підприємствах харчової промисловості широко використовуються тепломасообмінні апарати з безпосереднім контактом фаз. Ці апарати порівняно з рекуперативними теплообмінниками мають вищий коефіцієнт енергетичної ефективності, меншу металоємність конструктивно нескладні, а також можуть бути виготовлені $з$ неметалевих матеріалів. При використанні цього типу апаратів $є$ можливість створити нові високо- 
ефективні тепломасообмінні установки більшої потужності. Це дасть змогу полегшити умови праці за рахунок спрощення технічного обслуговування та зменшити забруднення довкілля.

3 усього різноманіття апаратів із безпосереднім контактом фаз, що експлуатуються в умовах харчової промисловості, для дослідження обрано пароконтактні тепломасообмінні апарати з розподільчими пристроями циліндричного типу. Цей тип теплообмінного обладнання дає змогу створити апарати, які забезпечують стабільне зрошення та максимальну поверхню контакту фаз у широкому діапазоні зміни витратних характеристик теплоносіїв.

Створення пароконтактних тепломасообмінних апаратів запропонованого типу і розроблення теплообмінників різної теплової потужності потребує науково обгрунтованих методик ї теплогідравлічних і конструктивних розрахунків. Це можливо тільки за умови коректного та науково достовірного дослідження і відповідного аналізу результатів проведеного дослідження.

Мета статті: порівняння результатів експериментального дослідження процесу конденсації пари 3 парогазової суміші на поверхні циліндричного вільностікаючого струменя рідини з кореляціями, наведеними в працях інших вчених.

Викладення основних результатів дослідження. Дослідження процесів теплообміну під час конденсації пари на циліндричному вільностікаючому струмені рідини відбувалося на дослідній установці, яка була виготовлена в Інституті вугільних технологій НАН і змонтована на кафедрі теплоенергетики та холодильної техніки Національного університету харчових технологій.

Дослідна установка дала змогу дослідити процеси теплообміну та гідродинамічні характеристики під час конденсації пари на циліндричному вільностікаючому струмені рідини в межах змін витратних і режимних параметрів потоків рідини та водяної пари, максимально наближених до режимів роботи теплообмінного обладнання харчової промисловості, а саме:

- тиск насиченої водяної пари в межах $101 \ldots 114$ кПа;

- кінетична енергія набігаючого потоку пари: досліди проводилися як за відсутності руху нагрівної пари, так і при значеннях динамічного напору $\rho_{\Pi} \cdot v_{\Pi}^{2}$ в межах до 5 кг/(м.сек $\left.{ }^{2}\right)$;

- початкова швидкість струменя рідини в межах $0,29 \ldots 1,25 \mathrm{~m} / \mathrm{c}$;

- діаметр струменя: 3 метою отримання залежності досліджуваних процесів від ступеня розвитку контакту фаз було досліджене витікання рідини 3 отворів діаметром 6, 8 та 10 мм;

- висота струменів рідини становила $250 \ldots .500$ мм.

Принципова схема дослідної установки наведена на рис. 1.

Отримані дослідні дані були опрацьовані відповідним чином за методиками досліджень, наведеними у працях таких вчених, як: І. В. Васильєв [3], В.Ф. Єрмолов [4], Г.А. Єресько [5], Н.С. Мочалова та ін.[6], S. Benedek [7], I. Iciek [8], В. П. Ісаченко та ін. [9; 10], De Salve [11]. Дослідження проводилися з урахуванням відповідних режимних параметрів пари та рідини, максимально наближених до умов роботи тепломасообмінного обладнання харчової промисловості, та з урахуванням діапазону зміни режимів руху речовин і геометричних параметрів струменя, найбільш наближеного до режиму проведеного 
експерименту. Під час теоретичного аналізу результатів досліду та порівняння експериментальних даних 3 кореляціями, наведеними в працях інших вчених, були побудовані графічні залежності. Встановлено, що описати дослідні дані існуючими кореляціями неможливо, оскільки наявна значна невідповідність даних, розрахованих за існуючими кореляціями, і даних, отриманих під час експерименту. Розсіювання значень у більшості випадків перевищує $\pm 25 \%$, а в окремих випадках - досягало близько $70 \%$.

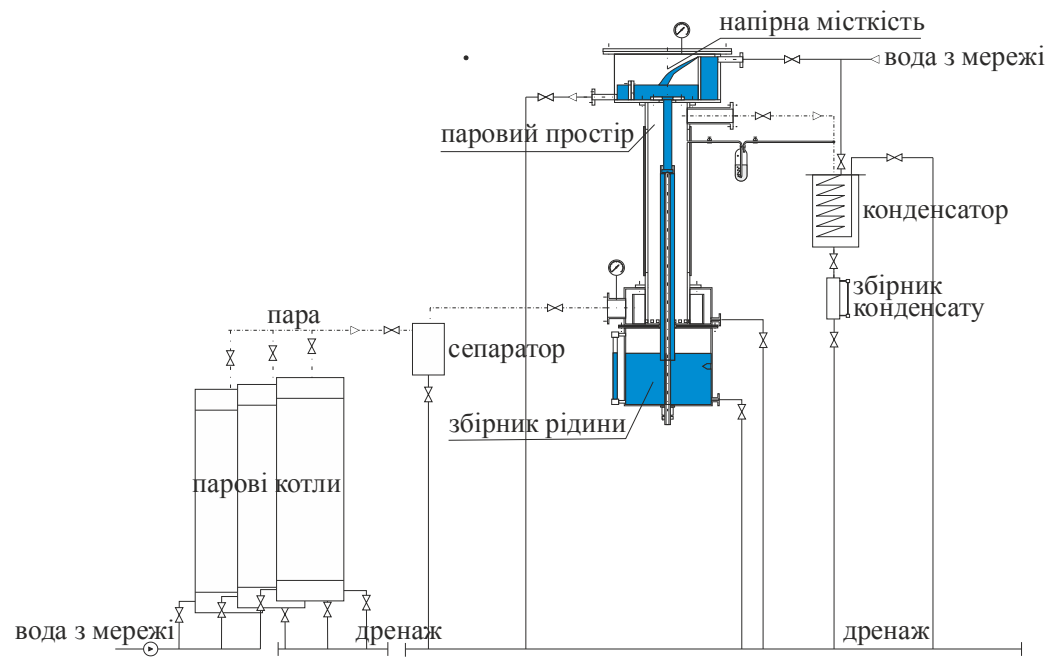

Рис. 1. Принципова схема дослідної установки

Графічне зображення наведеного порівняння та кореляційні залежності показано на рис. 2 -9.

1. Кореляційна залежність І.В. Васильєва:

$$
\begin{aligned}
& \lg \frac{t_{s}-t_{1}}{t_{s}-t_{2}}=0,029\left(\frac{g d_{0}}{v_{0}^{2}}\right)^{0,2}\left(\frac{l}{d_{0}}\right)^{0,7} . \\
& \text { оозр. }
\end{aligned}
$$

Рис. 2. Порівняння експериментальних даних з кореляцією І.В. Васильєва

2. Кореляційна залежність В.Ф. Срмолова:

$$
\lg \frac{t_{s}-t_{1}}{t_{s}-t_{2}}=0,085 \frac{I}{d_{0}} \mathrm{La}^{0,33} \mathrm{~K}^{-0,13} \mathrm{Pr}^{-0,62} \mathrm{Fr}^{-0,33} \text {. }
$$




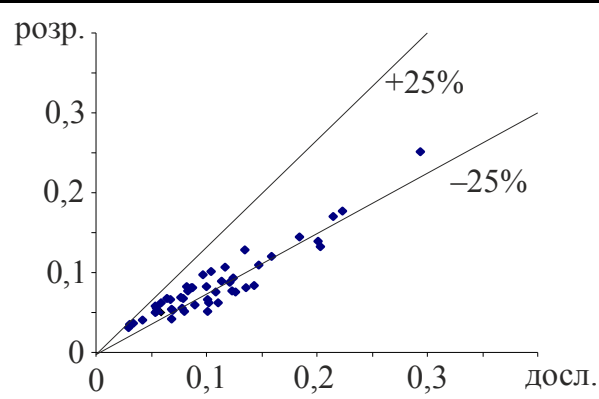

Рис. 3. Порівняння експериментальних даних з кореляцісю В.Ф. Срмолова

3. Кореляційна залежність Г.А. Єресько:

$$
\frac{t_{s}-t_{1}}{t_{s}-t_{2}}=1,71 \cdot \mathrm{Fr}^{-0,05} \operatorname{Pr}^{-0,08}\left(\frac{d_{0}}{D_{0}}\right)^{-0,24} .
$$

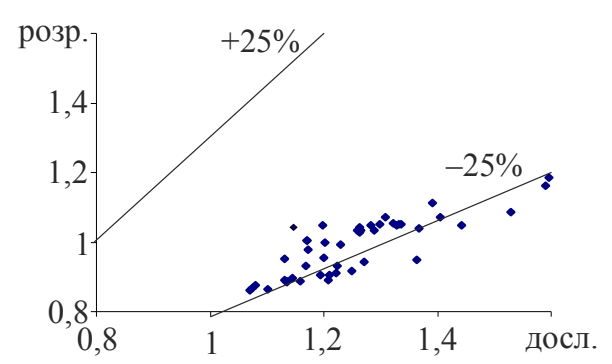

Рис. 4. Порівняння експериментальних даних з кореляцією Г.А. Ересько

4. Кореляційна залежність Н. С. Мочалова та ін.:

$$
\mathrm{St}=0,047\left(\frac{l}{d_{0}}\right)^{-0,52} \operatorname{Re}^{-0,0033} \operatorname{Pr}^{-0,074} \operatorname{Fr}^{-0,064} \text {. }
$$

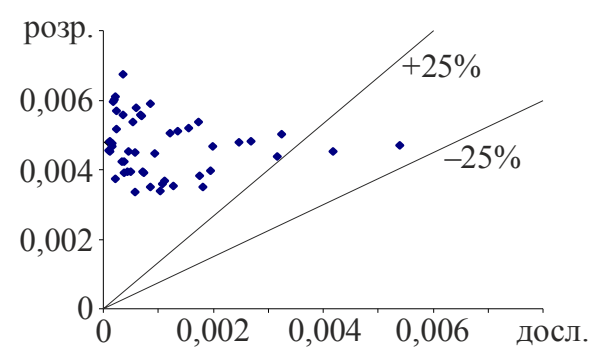

Рис. 5. Порівняння експериментальних даних з кореляцією Н.С. Мочалова

5. Кореляційна залежність S. Benedek:

$$
\mathrm{St}_{\mathrm{c} 3}=0,00286\left(\frac{S}{F}\right)^{0,06} K^{0,084} \text {. }
$$




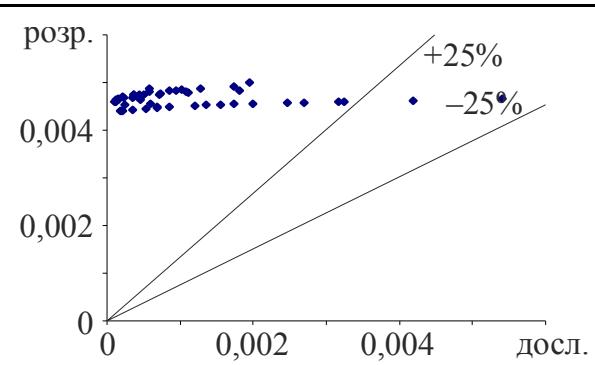

Рис. 6. Порівняння експериментальних даних 3 кореляцісю S. Benedek

6. Кореляційна залежність I. Iciek:

$$
\mathrm{St}=0,00375\left(\frac{I}{D}\right)^{-0,28} \mathrm{Fr}^{-0,10} \text {. }
$$

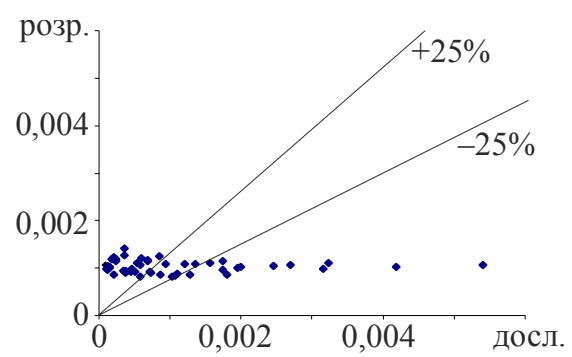

Рис. 7. Порівняння експериментальних даних 3 кореляцією I. Iciek

7. Кореляційна залежність В.П. Ісаченка та ін.:

$$
4 \mathrm{St}_{\mathrm{cp}}=3,3\left(\frac{l}{d_{0}}\right)^{-0,59} \operatorname{Re}^{-0,27} K^{-0,44} \operatorname{Pr}^{-0,5} \exp (0,16 \mathrm{We}) \text {. }
$$

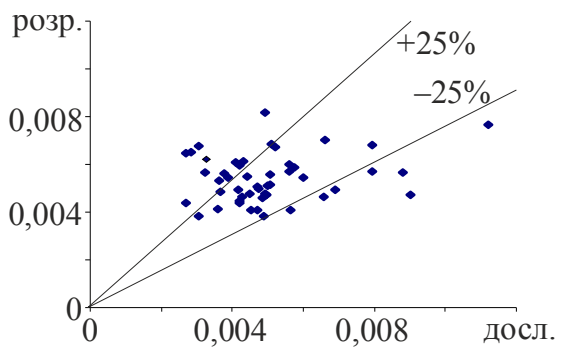

Рис. 8. Порівняння експериментальних даних 3 кореляцісю В.П. Исаченка та ін.

8. Кореляційна залежність De Salve:

$$
\mathrm{St}=3,25\left(\frac{I}{d}\right)^{-0,52} \operatorname{Re}^{-0,38} K^{-0,19} \operatorname{Pr}^{-0,52} .
$$




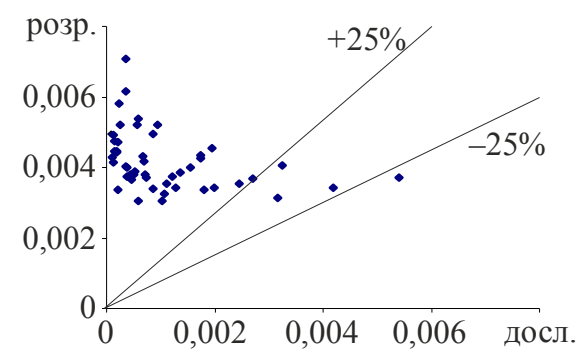

Рис. 9. Порівняння експериментальних даних з кореляцісю De Salve

\section{Висновок}

У результаті аналізу можна зробити висновок, що використання існуючих моделей для узагальнення дослідних даних проведеного експерименту неможливе. Тобто на сьогодні не існує моделі, яка б $з$ достовірною точністю описувала процеси теплообміну під час конденсації пари на циліндричному вільностікаючому струмені рідини для тих режимів руху водяної пари та води, в межах яких було проведено експеримент.

\section{Література}

1. Исаченко В.П. Теплообмен при конденсации пара на сплошных и диспергированных струях жидкости / В.П. Исаченко, А.П. Солодов // Теплоэнергетика. — 1972. — № 9. C. $24-27$.

2. Вукалович М.П. Таблицы теплофизических свойств воды и водяного пара / М.П. Вукалович, С.Л. Ривкин, А.А. Александров. - Москва : Изд. стандартов, 1969. — 408 с.

3. Зингер H.M. О нагреве струи воды в паровом пространстве // Вопросы теплообмена при изменении агрегатного состояния вещества. - Москва : Госэнергоиздат, 1953. C. $81-91$.

4. Ермолов В.Ф. Экспериментальное исследование тепло- и массообмена в пучке струй воды, омываемых поперечным потоком пара или паровоздушной смеси при вакууме // Труды ЦКТИ. - 1965. - Вып. 63. - С. 53-63.

5. Ересько Г.А. Нагрев струй жидкости паром // Известия вузов. Энергетика. - 1965. № 1. - C. 44-46.

6. Мочалова Н.С. Теплообмен при конденсации пара на турбулентных струях жидкости с учетом входного участка / Н.С. Мочалова, Л.Н. Холпанов, В.А. Малюсов, Н.М. Жаворонков // Инженерно-физический журнал. - 1983. - Т. 44, № 6. - С. 901-908.

7. Benedek $S$. Heat transfer at the condensation of steam on turbulent water jet. // Int. J. Heat and Mass Transfer. - 1976. - V. 19. - P. 448-450.

8. Iciek $J$. The hydrodynamics of a free liquid jet and their influence on direct contact heat transfer - III. Direct contact heating of a cylindrical free falling liquid jet.// Int. J. Multiphase Flow. - 1983. - V. 9. - P. 167-179.

9. Исаченко В.П. Исследование теплообмена при конденсации водяного пара на турбулентных струях воды / В.П. Исаченко, С.А. Сотсков, Е.В. Якушева // Труды МЭИ. 1975. - Вып. 235. - С. 145-152.

10. Исаченко В.П. Исследование теплообмена при конденсации пара на турбулентных струях жидкости / В.П. Исаченко, А.П. Солодов, Ю.З. Самойлович, В.И. Кушнырев, С.А. Сотсков // Теплоэнергетика. - 1971. - № 2. - С. 7-10.

11. Kim S. and Mills A.F. Condensation on coherent turbulent liquid jets: Part I Experimental Study // ASME Journal of Heat Transfer. — 1989. — V. 111. - P. 1068 - 1074. 